\title{
Clinical and bacteriological characteristics of infective endocarditis in the elderly
}

Christine Selton-Suty, Bruno Hoen, Alain Grentzinger, Philippe Houplon, Michel Maignan, Yves Juillière, Nicolas Danchin, Philippe Canton, François Cherrier

\begin{abstract}
Objective-To determine the clinical and bacteriological features of infective endocarditis in the elderly.

Design-Prospective case series.

Setting-A university hospital that is both a referral and a primary care centre.

Patients -114 consecutive patients treated for infective endocarditis from November 1990 to December 1993: 25 were $>70$ years of age (group 1 ) and 89 were $<70$ years old (group 2).

Results-Location of infective endocarditis, clinical signs, and symptoms were similar in the two groups, except for a lower occurrence of embolic episodes in the elderly (group 1: $8 \%$, group 2: $28 \%$; $P<$ $0.04)$. A higher rate of infective endocarditis on intracardiac prosthetic devices was noted in group 1 (group 1: $52 \%$, group 2: $25 \% ; P<0.05)$. The distribution of causative micro-organisms showed a higher proportion of bacteria from the gastrointestinal tract in the elderly (group D streptococci and enterococci: $48 \%$ in group 1 v $20 \%$ in group 2) and the presumed portal of entry was more often digestive (group 1: $50 \%$, group 2: $17 \% ; P=0.01)$. Elderly patients were less often operated on (group 1: $24 \%$, group 2: $43 \% ; P=0.07$ ) and their mortality rate was higher (group 1: $28 \%$, group 2: $13 \% ; P=0.08)$.

Conclusions-Infective endocarditis in patients over 70 often occurs in those with intracardiac prosthetic devices and is more often due to bacteria from the gastrointestinal tract. Its prognosis appears to be worse than in younger subjects.
\end{abstract}

(Heart 1997;77:260-263)

Department of Cardiology, CHU Brabois, Nancy, France C Selton-Suty A Grentzinger P Houplon Y Juillière

N Danchin

F Cherrier

Department of Infectious Disease B Hoen

M Maignan

P Canton

Correspondance to:

Nancy-Brabois, Cardiologie

Nancy-Brabois, Cardiologie

Nancy, France.

Accepted for publication

10 October 1996

Recent studies have shown remarkable changes in epidemiological and clinical features of infective endocarditis. In the $1950 \mathrm{~s}^{1}$ its incidence was maximal in 20-30 year old patients and only $5 \%$ of patients were over 60 . Nowadays, ${ }^{23}$ the incidence of infective endocarditis has increased dramatically in patients older than 50 years, reaching a peak at 70-74 years. As life span is progressively increasing, this trend is likely to continue. From the clinical standpoint ${ }^{4-6}$ the diagnosis of infective endocarditis is often more difficult in older patients because some of their symptoms (asthenia, anorexia, weight loss, presence of a cardiac murmur, and so on) may be erroneously attributed to the "old age", or because some signs can mimic those of other diseases. Therefore it seemed worthwhile to analyse potential age related distinctive features of infective endocarditis with respect to clinical variables, bacteriological data, and in-hospital course.

\section{Methods}

From November 1990 to November $1991,{ }^{3}$ a prospective survey of infective endocarditis was conducted in three administrative regions of France. All patients treated for infective endocarditis during this period in our region (Lorraine, 2.3 million population) were included in the present study. In addition, from November 1991 to December 1993, prospective recording of infective endocarditis continued in the cardiology department and the department of infectious disease of the only university hospital of this region, using the same inclusion criteria. This hospital is both a tertiary referral centre for the region and a primary care centre for the local population. All patients who were considered to have infective endocarditis by their attending practitioners and treated for infective endocarditis were included. Two groups were considered with respect to age: group 1 patients were 70 years of age or older, and group 2 patients were under 70 and over 15 years of age. For each patient, the following data were recorded: age, sex, known pre-existing heart disease, previous episode of infective endocarditis, site of infective endocarditis, presence of fever, ? auscultatory change or extra cardiac manifes- $N$ tations, echocardiographic data, number of $\mathrm{\omega}^{N}$ blood cultures performed and number of positive blood cultures, responsible micro-organ- 0 ism, presumed portal of entry, duration of initial hospital stay, need for surgery, and ? death. In addition, all cases were classified according to the Duke criteria. ${ }^{7}$

\section{STATISTICAL ANALYSIS}

Quantitative variables were compared using Student's tests; $\chi^{2}$ or Fisher exact tests were 8 used when appropriate for qualitative variables comparison. A $\mathrm{P}$ value $<0.05$ was considered significant. In addition, in order to assess the specific role of age on in-hospital mortality, a multivariate (stepwise regression) analysis including all the variables that were shown to be different between the two groups (age, 
Table 1 Distribution of diagnostic categories, underlying heart disease and location of infective endocarditis in patients over (group 1) and under (group 2) 70 years of age. Values are means (\%)

\begin{tabular}{|c|c|c|c|}
\hline & $\begin{array}{l}\text { Group 1 } \\
(n=25)\end{array}$ & $\begin{array}{l}\text { Group 2 } \\
(n=89)\end{array}$ & $P$ value \\
\hline \multicolumn{4}{|l|}{ Diagnostic category (Duke criteria): } \\
\hline Pathologically definite & $1(4 \cdot 0)$ & $26(29 \cdot 2)$ & \multirow{3}{*}{$<0.05$} \\
\hline Clinically definite & $21(84 \cdot 0)$ & $53(59 \cdot 6)$ & \\
\hline Possible & $3(12 \cdot 0)$ & $10(11 \cdot 2)$ & \\
\hline \multicolumn{4}{|l|}{ Underlying heart disease: } \\
\hline Prosthetic devices & $13(52 \cdot 0)^{\star}$ & $22(24 \cdot 7) \dagger$ & \multirow{7}{*}{$<0.05$} \\
\hline No previously known heart disease & $5(20 \cdot 0)$ & $32(36 \cdot 0)$ & \\
\hline Native valve disease & $7(28 \cdot 0)$ & $35(39 \cdot 3)$ & \\
\hline Mitral disease & $\mathrm{n}=5$ & $\mathrm{n}=16$ & \\
\hline Aortic disease & $\mathrm{n}=2$ & $\mathrm{n}=8$ & \\
\hline Mitral and aortic disease & $\mathrm{n}=0$ & $\mathrm{n}=6$ & \\
\hline Congenital cardiac disease & $\mathrm{n}=0$ & $\mathrm{n}=3$ & \\
\hline \multicolumn{4}{|l|}{ Location: } \\
\hline Mitral & $10(40 \cdot 0)$ & $37(41 \cdot 6)$ & \multirow{4}{*}{ NS } \\
\hline Aortic & $10(40 \cdot 0)$ & $23(25 \cdot 8)$ & \\
\hline Mitral and aortic & $1(4 \cdot 0)$ & $15(16.9)$ & \\
\hline Other & $4(16 \cdot 0)$ & $14(15 \cdot 7)$ & \\
\hline
\end{tabular}

«Nine patients with valve prostheses, three patients with pacemaker, one patient with both. $\dagger 20$ patients with valve prostheses, two patients with pacemaker.

Table 2 Clinical signs and echocardiographic findings in patients over (group 1) and under (group 2) 70 years of age. Values are means (\%)

\begin{tabular}{|c|c|c|c|}
\hline & $\begin{array}{l}\text { Group 1 } \\
(n=25)\end{array}$ & $\begin{array}{l}\text { Group 2 } \\
(n=89)\end{array}$ & Pvalue \\
\hline Fever & $20(80 \cdot 0)$ & $80(89.9)$ & \\
\hline Auscultatory changes & $19(76 \cdot 0)$ & $71(79 \cdot 8)$ & \\
\hline Extracardiac manifestations: & $16(64 \cdot 0)$ & $63(70 \cdot 8)$ & \\
\hline Petechiae & $1(4 \cdot 0)$ & $12(13.5)$ & \\
\hline Haematuria & $5(20 \cdot 0)$ & $22(24 \cdot 7)$ & \\
\hline Splenomegaly & $7(28 \cdot 0)$ & $13(14 \cdot 6)$ & \\
\hline Embolus ${ }^{\star}$ & $2(8.0)$ & $25(28 \cdot 1)$ & $<0.04$ \\
\hline Subungual haemorrhages & 0 & $2(2 \cdot 2)$ & \\
\hline Conjunctival haemorrhages & 0 & 0 & \\
\hline Roth spots & 0 & $1(1 \cdot 1)$ & \\
\hline Aseptic meningitis & 0 & $5(5 \cdot 6)$ & $\dagger$ \\
\hline Glomerulonephritis & 0 & $8(9 \cdot 0)$ & 1 \\
\hline Osler nodes & 0 & $2(2 \cdot 2)$ & \\
\hline Janeway lesions & 0 & $1(1 \cdot 1)$ & \\
\hline \multicolumn{4}{|l|}{ Echocardiographic findings: } \\
\hline Vegetation & $15(60)$ & $69(77)$ & $<0.08$ \\
\hline Ring abscess & 0 & $5(6)$ & \\
\hline Valve insufficiency $(>2)$ & $13(62)$ & $53(62)$ & \\
\hline
\end{tabular}

${ }^{\star}$ Group 1: two cerebral emboli; group 2: 25 patients with 31 episodes: nine cerebral, five peripheral, four pulmonary, six cerebral and peripheral.

tMicro-organisms responsible for these cases were Staphylococcus aureus in two cases Streptococcus bovis in one case, group G streptococcus in one case, and blood cultures remained negative in one case.

Table 3 Distribution of causative micro-organisms for infective endocarditis in patients over (group 1) and under (group 2) 70 years of age. Values are means (\%)

\begin{tabular}{|c|c|c|}
\hline & $\begin{array}{l}\text { Group } 1 \\
(n=21)\end{array}$ & $\begin{array}{l}\text { Group 2 } \\
(n=77)\end{array}$ \\
\hline $\begin{array}{l}\text { Gp D streptococci and } \\
\text { enterococci }\end{array}$ & $\begin{array}{l}10(47 \cdot 6) \\
\text { Streptococcus bovis }(\mathrm{n}=8) \\
\text { Enterococcus faecalis }(\mathrm{n}=2)\end{array}$ & $\begin{array}{l}15(19 \cdot 5) \\
\text { Streptococcus bovis }(11) \\
\text { Enterococcus faecalis }(3) \\
\text { Enterococcus faecium }(1)\end{array}$ \\
\hline Staphylococci & $\begin{array}{l}5(23 \cdot 8) \\
\text { aureus }(\mathrm{n}=3) \\
\text { lugdunensis }(\mathrm{n}=1) \\
\text { non-identified }(\mathrm{n}=1)\end{array}$ & $\begin{array}{l}27(35 \cdot 1) \\
\text { aureus }(\mathrm{n}=18), \\
\text { epidermidis }(\mathrm{n}=5), \\
\text { hominis }(\mathrm{n}=1), \text { xylosus }(\mathrm{n}=1) \text {, } \\
\text { coagulase negative }(\mathrm{n}=2)\end{array}$ \\
\hline Viridans streptococci & $\begin{array}{l}3(14 \cdot 3) \\
\text { mutans }(\mathrm{n}=2), \text { milleri }(\mathrm{n}=1)\end{array}$ & $\begin{array}{l}19(24 \cdot 7) \\
\text { mutans }(\mathrm{n}=2), \text { milleri }(\mathrm{n}=1) \text {, } \\
\text { sanguis }(\mathrm{n}=10), \text { mitis }(\mathrm{n}=4) \text {, } \\
\text { unspecified }(\mathrm{n}=2)\end{array}$ \\
\hline Other streptococci & $0(0)$ & $\begin{array}{l}10(13 \cdot 0) \\
\text { pneumoniae }(\mathrm{n}=3) \\
\text { group } \mathrm{B}(\mathrm{n}=4) \\
\text { group } \mathrm{G}(\mathrm{n}=1) \\
\text { non-identified }(\mathrm{n}=2)\end{array}$ \\
\hline Other micro-organisms ${ }^{\star}$ & $\begin{array}{l}3(14 \cdot 3) \\
\text { Cardiobacterium hominis }(\mathrm{n}=1), \\
\text { Campylobacter fetus }(\mathrm{n}=1) \\
\text { Corynebacterium jeikeium }(\mathrm{n}=1)\end{array}$ & $\begin{array}{l}6(7 \cdot 8) \\
\text { Coxiella burnetii }(\mathrm{n}=2), \\
\text { Bacillus pumilus }(\mathrm{n}=1), \\
\text { Propionibacterium acnes }(\mathrm{n}=1), \\
\text { Gemella haemolysans }(\mathrm{n}=1), \\
\text { Candida sp }(\mathrm{n}=1)\end{array}$ \\
\hline
\end{tabular}

${ }^{\star} \chi^{2}=10 \cdot 04,4$ degrees of freedom, $\mathrm{P}<0 \cdot 04$

underlying heart disease, occurrence of an embolic event, presence of a vegetation, type of micro-organisms) was performed on the whole study population (group $1+$ group 2 ). Values are given as mean (SD).

\section{Results}

Of the 114 patients, 25 (22\%) belonged to group 1 (mean age: 76 (6) years, range 70 to $91 ; 16(64 \%)$ male, 9 (36\%) female), and 89 to group 2 (mean age: 51 (15) years, range 19 to $69 ; 59$ (66\%) male, 30 (34\%) female). According to the Duke criteria, the distribution of diagnostic categories was significantly different in the two groups, with a lower percentage of definite infective endocarditis in group 1 (table 1).

The distribution of underlying heart disease was significantly different between the two groups. Infective endocarditis on intracardiac prosthetic devices (valve prostheses or pacemakers) was more common in group 1 than in group 2. The location of infective endocarditis was similar in the two groups (table 1). No group 1 patient and four group 2 patients had been operated on during the two months before the episode of infective endocarditis (NS). Two group 1 and six group 2 patients had a history of previous infective endocarditis (NS). The two groups did not differ with respect to the presence of fever, auscultatory changes, and extracardiac manifestations (table 2). Among extracardiac manifestations, the only significant difference between the two groups was the three times lower incidence of embolic events in group 1. Although there was a trend toward a lower rate of vegetations in the elderly, echocardiographic findings were not significantly different between the two groups (table 2).

The total number of blood cultures $(6 \cdot 8$ $(4 \cdot 2)$ in group $1 v 7 \cdot 2(4 \cdot 3)$ in group 2 ; NS) and the mean number of positive blood cultures $(3.6(2.3)$ in group $1 v 3.3(2.8)$ in group 2 ; NS) were similar in the two groups, as well as the percentage of patients with negative blood cultures (five (20\%) in group $1 v 13$ $(15 \%)$ in group 2 ; NS). Responsible microorganisms were identified in 21 group 1 patients and 77 group 2 patients. Their distribution showed a significantly higher percentage of group D streptococci and enterococci in group 1 than in group 2 (table 3 ).

A presumed portal of entry was reported in 14 group 1 patients (56\%) and 60 group 2 patients $(67 \%)$ (NS). Their distribution was similar in the two groups except that a digestive portal of entry was more often found in group 1 (7/14 in group $1 v 10 / 60$ in group 2; $\vec{P}=0.01)$. Only five group 1 patients were drug addicts (table 4).

The mean duration of hospital stay was 59 (27) days in group 1 and 58 (34) in group 2 (NS). At the end of the initial hospital admission, six group 1 patients (24\%) and 38 group 2 patients $(43 \%)$ had undergone valve surgery $(\mathbf{P}=0.07)$. Indications for surgery in group 1 were persistent fever in two cases, heart failure or significant regurgitation in three cases, and for both reasons in one patient. In group 2, 21 patients were operated on because of haemodynamic disorders; these were associated with persistent infection in nine other patients. High risk of embolic events led to surgery in three patients, associated with heart failure in two, and with persistent fever in two others. In 
Table 4 Presumed portal of entry of infective endocarditis in patients over (group 1) and under (group 2) 70 years of age. Values are means (\%)

\begin{tabular}{llll}
\hline & $\begin{array}{l}\text { Group 1 } \\
(n=14)\end{array}$ & $\begin{array}{l}\text { Group 2 } \\
(n=60)\end{array}$ & $\begin{array}{l}\text { Pvalue } \\
\text { (Fisher exact test) }\end{array}$ \\
\hline Digestive & $7(50)$ & $10(16 \cdot 7)$ & $0 \cdot 01$ \\
Dental & $2(14 \cdot 3)$ & $19(31 \cdot 1)$ & $0 \cdot 17$ \\
Iatrogenic & $3(21 \cdot 4)$ & $14(23 \cdot 0)$ & $0 \cdot 59$ \\
Cutaneous & $1(7 \cdot 1)$ & $9(14 \cdot 8)$ & $0 \cdot 39$ \\
Other* & $1(7 \cdot 1)$ & $8(13 \cdot 4)$ & $0 \cdot 46$ \\
\hline
\end{tabular}

${ }^{\star}$ Other portals of entry were urological in one case, ear-nose-throat in two cases (one group 1 and group 2), gynaecological in one case, and drug abuse in five cases $(8 \cdot 2 \%)$.

this subset of patients who were operated on, responsible micro-organisms were distributed as follows: group 1, staphylococci (2), streptococci (2), Cardiobacterium hominis (1); there was one negative blood culture; group 2: staphylococci (12), streptococci (21); there were five negative blood cultures.

Seven group 1 patients $(28 \cdot 0 \%)$ and 12 group 2 patients $(13.5 \%)$ died in hospital $(P=0.08)$. Of patients operated on, three group 1 patients $(50 \%)$ and six group 2 patients $(16 \%)$ died in the postoperative period $(P=0.09)$.

Multivariate analysis showed that age $(P=$ $0.02)$ and the presence of at least one vegetation at echocardiography $(P=0.04)$ were independent risk factors for fatal outcome.

\section{Discussion}

Diagnosis of infective endocarditis often remains difficult, and practitioners are sometimes prompted to diagnose and treat patients on the basis of clinical and bacteriological findings, even when they do not fit a validated diagnostic classification. Our population was selected according to that pragmatic scheme. When retrospectively applying the Duke criteria, ${ }^{7}$ none of our patients was rejected, confirming the appropriate clinical relevance of these new definition criteria. ${ }^{8}$ In our study, the lower percentage of definite infective endocarditis in the elderly is, from the evidence, due to the lower rate of valve surgery in this group resulting in the absence of histological confirmation of infective endocarditis.

Age has already been proven to be an important risk factor for infective endocarditis. In a community cohort, ${ }^{9}$ the incidence rate ratio was of 8.8:1 for age of 65 years or older versus less than 65 years. The mean age of patients developing infective endocarditis is notably increasing over time: about 30 years in the $1950 \mathrm{~s},{ }^{1} 50$ years in the $1980 \mathrm{~s},{ }^{10}{ }^{11}$ and 55 to 60 years in the most recent studies. ${ }^{2}{ }^{3}$ The changing pattern of underlying heart disease may be the most relevant explanation for this trend. ${ }^{58}$ Population aging is responsible for increasing numbers of people with atheromatous and calcific valve disease. The decreasing incidence of rheumatic fever has resulted in a decline in new cases of rheumatic heart disease. Finally, the implantation of intracardiac prosthetic devices has became increasingly frequent in recent years. Other factors such as increasing incidence of nosocomial bacteraemia and an impaired host immune system in the elderly may also contribute. Whether antibiotic prophylaxis is cor- rectly prescribed in the elderly may also be questioned.

Despite the lower male to female ratio in the elderly, the proportion of men with infective endocarditis remained high in our study group 1 , suggesting that male gender may be an independent important risk factor for infective endocarditis.

The distribution of underlying heart disease showed a significantly higher rate of infective $\vec{F}$ endocarditis on intracardiac prosthetic devices $\stackrel{?}{?}$ in the elderly. This probably results from the high prevalence of prosthetic valves in elderly $\frac{\bar{\sigma}}{\bar{\omega}}$ patients, who more often need medical care $\frac{\bar{\sigma}}{\bar{\sigma}}$ and are consequently more likely to undergo $\curvearrowright$ invasive procedures than younger patients. Elderly patients with intracardiac prosthetic $\overrightarrow{0}$ devices should be considered at high risk for infective endocarditis. ${ }^{12} 13$

Among clinical features described in infective endocarditis, the only age related charac-? teristic was the lower rate of emboli in the elderly. This relation between age and periph- $w$ eral embolisation was previously noted by Sanfilippo and Werner. ${ }^{13} 14$ This may be related응 to the lower rate of vegetations in the elderly, which might be due to the specific distribution? of micro-organisms in this population. In fact, ${ }^{15} \stackrel{\frac{0}{3}}{\circ}$ Steckelberg has already shown that vegetations ${ }^{3}$ were less frequent in cases of endocarditis due $\vec{\theta}$ to Staphylococcus aureus, enterococci, and non-.enterococcal group D streptococci, which were the most frequent causative micro-organisms in the elderly in our study.

One of the most important findings in our study was the high percentage of infective $\stackrel{\perp}{\perp}$ endocarditis due to group D streptococci or $\overrightarrow{\vec{B}}$ with a digestive portal of entry in the elderly. 3 The high prevalence of Streptococcus bovis endo-? carditis in the elderly and its relation with pre-? existing bowel lesions have been described in previous studies. ${ }^{12}{ }^{1316-18}$ Furthermore, enterococcal endocarditis, which is commonly related to a urinary tract or gastrointestinal source, $\overline{3}$ often occurs in old patients and is frequentlyo nosocomial. ${ }^{19}$ In addition, Chen reported that $₹$ patients with nosocomial endocarditis tendedo to be older than those with community acquired endocarditis. ${ }^{20}$ Accordingly, an appro-o priate antibiotic regimen using ampicillin or glycopeptides rather than penicillin might berecommended in those patients until the results 0 of blood cultures are obtained.

Our $15 \cdot 8 \%$ rate of cases with negative bloodo cultures is another point for discussion. This iso higher than found in other recent series. ${ }^{2} \frac{\mathrm{\Phi}}{}$ However, the $1 \%$ rate of blood culture negative? infective endocarditis recorded by van der Meer ${ }^{0}$ et al is obviously related to their study's case $\frac{\overrightarrow{\mathbb{D}}}{\mathrm{O}}$ recruitment design, which was based on the $\stackrel{?}{?}$ positive blood cultures found by micro- $\stackrel{\mathbb{Q}}{\circ}$ biologists. Besides, a survey conducted in? France during the same period and a recent?

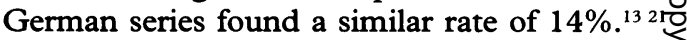
This higher rate was mostly explained by the high frequency of antibiotic administration? before drawing blood cultures; the responsibility of poorly growing bacteria was only marginal, although serological testing for those organisms was not exhaustive. 
Age remains an independent factor in mortality among the whole population. However, the management of infective endocarditis differs in elderly versus younger patients. As could be anticipated - although rapid surgical intervention is increasingly advocated for infective endocarditis-elderly patients are less often surgically treated than younger patients. This restricted usage of surgery in elderly patients is probably responsible for the poor initial prognosis observed in our series as well as in others. ${ }^{12223}$ In the recent study of Werner, the frequency of surgery was comparable among the different groups of age, ${ }^{13}$ and the global mortality was not different in these groups, even though the mortality of medically treated patients older than 70 years was relatively high (75\%).

\section{CONCLUSION}

The role of micro-organisms originating from the gastrointestinal tract should be especially considered in infective endocarditis in the elderly. The prognosis of infective endocarditis is worse in the elderly than in younger patients. Therefore, efforts should be made towards better prophylaxis: detection of colonic lesions, ${ }^{24}$ use of antibiotic prophylaxis especially in gastrointestinal investigations, and prevention of nosocomial infection by proper use of invasive procedures in an aged population. Increased use of surgical procedures may also improve prognosis in the elderly.

1 Anderson HJ, Staffurth JS. Subacute bacterial endocarditis in the elderly. Lancet 1955;i:1055-8.

2 van der Meer JTM, Thompson J, Valkenburg HA, Michel MF. Epidemiology of bacterial endocarditis in the Netherlands. I. Patients characteristics. Arch Intern Med 1992;152:1863-8.

3 Delahaye F, Goulet V, Lacassin F, Ecochard R, SeltonSuty C, Hoen B, et al. Characteristics of infective endocarditis in France in 1991: a one-year survey. Eur Heart $\mathcal{F}$ 1995;16:394-401.

4 Thell R, Martin FH, Edwards JE. Bacterial endocarditis in subjects 60 years of age and older. Circulation 1975;51 174-82.
5 Gantz NM. Geriatric endocarditis: avoiding the trend toward mismanagement. Geriatrics 1991;46:66-8.

6 Tenenbaum MJ, Kaplan MH. Infective endocarditis in the elderly: an update. Geriatrics 1984;39:121-7.

7 Durack DT, Lukes AS, Bright DK. New criteria for diagnosis of infective endocarditis: utilisation of specific echocardiographic findings. Am $₹$ Med 1994;96:200-9.

8 Bayer AS, Ward JI, Ginzton LE, Shapiro SM. Evaluation of new clinical criteria for the diagnosis of infective endocarditis. Am $\mathcal{F}$ Med 1994;96:211-9.

9 Steckelberg JM, Melton LJ, Ilstrup DM, Rouse MS, Wilson WR. Influence of referral bias on the apparent clinical spectrum of infective endocarditis. $A m \mathcal{F} \mathrm{Med}$ 1990;88:582-8.

10 Goulet V, Etienne J, Fleurette J, Netter R. L'endocardite infectieuse en France: caractéristiques épidémiologiques. Presse Med 1986;15:1855-8.

11 McKinsey DS, Ratts TE, Bisno AL. Underlying cardiac lesions in adults with infective endocarditis. The changlesions in adults with infective endocardis

12 Terpenning MS, Buggy BP, Kauffman CA. Infective endocarditis:clinical features in young and elderly patients. Am F Med 1987;83:626-34.

13 Werner GS, Schulz R, Fuchs JB, Andreas S, Prange H, Ruschewski W, et al. Infective endocarditis in the elderly in the era of transesophageal echocardiography: clinical features and prognosis compared with younger patients. $A m$ $\Im$ Med 1996;100:90-7.

14 Sanfilippo AJ, Picard MH, Newell JB, Rosas E, Davidoff R, Thomas $\mathrm{JD}$, et al. Echocardiographic assessment of complications. F Am Coll Cardiol 1991;18:1 191-9.

15 Steckelberg JM, Murphy JG, Ballard D, Bailey K, Tajik J, Talierco CP, et al. Emboli in infective endocarditis: the prognostic value of echocardiography. Ann Intern Med 1991;114:635-40.

16 Hoen B, Briançon S, Delahaye F, Terhe V, Etienne J, Bigard M-A, et al. Tumors of the colon increase the risk of developing Streptococcus bovis endocarditis: a case-control study. Clin Infect Dis 1994;19:361-2.

17 Murray HW, Roberts RB. Streptococcus bovis bacteremia and underlying gastrointestinal disease. Arch Intern Med 1978;138:1097-9.

18 Ballet M, Gevigney G, Garé JP, Delahaye F, Etienne J, Delahaye JP. Infective endocarditis due to Streptococcus bovis. A report of 53 cases. Eur Heart $\mathcal{f}$ 1995;16:1975-80.

19 Herzstein J, Ryan JL, Mangi RJ, Greco TP, Andriole VT. Optimal therapy for enterococcal endocarditis. $A m \mathcal{F} \mathrm{Med}$ 1984;76:186-91.

20 Chen SC, Dwyer DE, Sorrell TC. A comparison of hospital and community-acquired infective endocarditis. $A m$ Cardiol 1992;70:1449-52.

21 Hoen B, Selton-Suty C, Lacassin F, Etienne J, Briançon S, Leport $\mathrm{C}$, et al. Infective endocarditis in patients with negative blood culture: analysis of 88 cases from a oneyear nationwide survey in France. Clin Infect Dis 1995; 20:501-6.

22 Applefeld MM, Hornick RB. Infective endocarditis in patients over age 60 . Am Heart $\mathcal{f} 1974 ; 88: 90-4$

23 Robbins N, DeMaria A, Miller MH. Infective endocarditis in the elderly. South Med f 1980;73:1335-8.

24 Mandel JS, Bond JH, Church TR, Snover DC, Bradley GM, Schuman LM, et al. Reducing mortality from colorectal cancer by screening for fecal occult blood. $N$ Engl $\mathcal{F}$ Med 1993;328:1365-71. 